\title{
Selectivity of cyclodextrins as a parameter to tune the formation of pseudorotaxanes and micelles supramolecular assemblies. A systematic SANS study $\dagger$
}

\author{
G. Lazzara, ${ }^{* a}$ S. Prevost ${ }^{b c}$ and M. Gradzielski ${ }^{b}$ \\ Received 3rd March 2011, Accepted 20th April 2011 \\ DOI: 10.1039/c1sm05376k
}

\begin{abstract}
We studied the formation of polypseudorotaxanes formed with cyclodextrins (CDs) threading a copolymer chain that forms self-assembled structures in water. The size of the CD cavity was chosen such that it is block selective with respect to the formation of inclusion complexes and therefore in terms of altering the structure of the copolymer self-assemblies in a systematic fashion. Small angle neutron scattering (SANS) experiments provide a direct and clear picture of the shape and interactions of the copolymer micelles in the absence and the presence of various CDs. Moreover, the dissolution of copolymer micelles by $\mathrm{CD}$ addition was clearly described by a simple model which provides a tool for quantitative predictions. This study suggests the possibility of designing materials with tunable aggregation abilities in water, where the extent of aggregate formation is determined by the amount and type of added cyclodextrin.
\end{abstract}

\section{Introduction}

Within the supramolecular chemistry topic over the past few years attention has been devoted to designing supramolecular inclusion complexes. Polyrotaxanes and polypseudorotaxanes ${ }^{1-3}$ are representative examples of such superstructures. Polyrotaxanes are composed of multiple macrocycles including a polymer chain terminated by bulky stoppers to avoid the dethreading of the host molecules. Obviously, their formation requires complex synthetic routes and methods. Polypseudorotaxanes are formed with macrocycles threading a polymer chain without end groups; their reversible formation is controlled by weak interactions (usually hydrophobic in nature) between the macrocycle and the polymer. Several macrocycles are available for this purpose like calixarenes, ${ }^{4}$ crown-ethers, ${ }^{5}$ cucurbiturils, ${ }^{6}$ cyclodextrins (CDs) and so on. Among them, CDs are good candidates for this purpose as proved by several studies and they are also most interesting due to their easy accessibility. ${ }^{7-10}$ The inclusion complexes based on native cyclodextrins generate a reduction in the hydration of both the host and the

${ }^{a}$ Dipartimento di Chimica "S. Cannizzaro", Università degli Studi di Palermo, Viale delle Scienze pad 17, 90128 Palermo, Italy. E-mail: g.lazzara@unipa.it

${ }^{b}$ Stranski Laboratorium für Physikalische und Theoretische Chemie, Institut für Chemie, Technische Universität Berlin, Straße des 17. Juni 124, Sekr. TC 7, 10623 Berlin, Germany

'Helmholtz-Zentrum Berlin, Hahn-Meitner-Platz 1, 14109 Berlin, Germany

$\dagger$ Electronic supplementary information (ESI) available. See DOI: $10.1039 / \mathrm{c} 1 \mathrm{sm} 05376 \mathrm{k}$ guest and therefore the precipitation of the solid polypseudorotaxanes takes place. ${ }^{11}$

Polypseudorotaxanes can be designed to obtain smart materials with multiple stimuli-sensitivities ( $\mathrm{pH}$-, temperature-, redox-, photo-responsive) by adequately selecting the polymer and macrocycle size and chemical structure. ${ }^{12}$ Nonionic conventional surfactants, containing ethylene oxide (EO) units, were proved ${ }^{13}$ to be useful as an alternative to macromolecules in preparing CDbased supramolecular polyrotaxanes.

A particular type of water soluble polymers that has been widely studied due to their interesting temperature dependent aggregation properties, are poly(ethylene oxide)-poly(propylene oxide)-poly(ethylene oxide) (PEO-PPO-PEO) polymers, also known under one of their trade names as Pluronics. The formation of inclusion complexes of Pluronics with $\mathrm{CD}$ has been known for some while and for instance light scattering experiments have shown that, provided the CD cavity is large enough, the CD will thread preferentially the PPO part. ${ }^{14}$ As well the thermodynamics and the kinetics of the threading process have been studied, also showing that the efficiency of the threading process depends on the way of preparation. ${ }^{15}$ Furthermore polyrotaxanes have been prepared from Pluronics and have been employed as biodegradable networks. ${ }^{16}$ More recently a new cationic polyrotaxane consisting of multiple pentaethylenehexamine-grafted- $\alpha$-cyclodextrin rings threaded on Pluronics has formed thermo-sensitive micelles due to the thermal behaviour of propylene oxide (PO) units. ${ }^{17}$ Very recently also the formation of hollow nanospheres from Pluronic and $\beta$-cyclodextrin has been reported which has been ascribed to the formation of coil-rod inclusion complexes. ${ }^{18}$ Polyrotaxanes formed by multiple 
methylated $\alpha$-CD molecules and polyethylene oxide units endcapped with adamantyl groups form elastic hydrogels controlled by the hydrophobic aggregation of the CD molecules induced by temperature increase. ${ }^{19}$ The $\mathrm{CD}$ size triggers the aggregation of Pluronics due to the selective inclusion behaviour ${ }^{10,14,20,21}$ and the threading process depends also on the solvent nature. ${ }^{10}$ In general, it can be stated that the interaction of cyclodextrins with Pluronics can lead to a large variety of different and interesting situations.

Within this general issue we carried out a systematic SANS study, in which structural changes in the copolymer aggregates upon the $\mathrm{CD}$ addition were monitored. For a deeper comprehension of the copolymer/cyclodextrin interaction phenomena, several factors were varied in a systematic fashion. The effect of the cavity size of the $\mathrm{CD}$ on the copolymer aggregation was explored by choosing hydroxypropyl- $\alpha$-cyclodextrin (HP- $\alpha$-CD) and HP- $\beta-C D$, which exhibit a selective inclusion behaviour towards the EO (thinner polymer backbone) and PO (thicker polymer backbone) units of the Pluronics. Namely, the native and the modified $\beta-\mathrm{CDs}^{10,21-23}$ fit both the EO and the PO units, hindering the copolymer self-assembling; the native and the modified $\alpha$-CDs ${ }^{10,14,20}$ do not alter much the thermodynamics of micellization being able to incorporate only the EO units (the CD cavity is too small for the bulky PO based moiety). A sketch of the threading behaviour is given in Fig. 1. The effect of the CD degree of substitution (DS) was investigated for the HP- $\beta-C D$. The native CDs were not selected because the sparing solubility of their inclusion complexes in water makes them less interesting than the modified CDs. Indeed, soluble polypseudorotaxanes are more appealing for specific purposes like biomedical applications ${ }^{24}$ by considering also that Pluronics are non-toxic. It should be noted that the micellization of the PEO-PPO-PEO copolymers is largely determined by the length of their hydrophobic PPO block. ${ }^{25}$ Accordingly by interacting with the hydrophobic core, for instance by addition of a surfactant, one is able to modify the micellization behaviour ${ }^{26,27}$ and for sufficiently high amounts of added surfactant even to suppress micellization completely. ${ }^{28}$ The chosen copolymers are $\mathrm{EO}_{76} \mathrm{PO}_{29} \mathrm{EO}_{76}$ (F68), $\mathrm{EO}_{103} \mathrm{PO}_{39} \mathrm{EO}_{103}$ (F88) and $\mathrm{EO}_{132} \mathrm{PO}_{50} \mathrm{EO}_{132}$ (F108), which possess the same hydrophilic/hydrophobic ratio but different molecular weight. This means that our study addresses in a systematic way the effect of variations in polymer and CD architecture on the structure of the formed aggregates. This is of central importance for the understanding of such mixed co-assembling systems.

\section{SANS data analysis}

\section{Cyclodextrin solutions}

The cyclodextrins in $\mathrm{D}_{2} \mathrm{O}$ produce a rather low scattering intensity, which monotonically decreases with the scattering vector $(q)$. Considering the relatively low resolution of a SANS instrument (due to the limited $q$-range and the experimental smearing) and the small characteristic dimensions of the particles and their globular structure, the data were well described by noninteracting monodisperse spherical particles

$$
I_{\mathrm{Sph}}(q)={ }^{1} N\left|F\left(q, R_{\mathrm{Sph}}\right)\right|^{2}+I_{\mathrm{bck}}
$$

where ${ }^{1} N$ is the number density of the particles calculated by using their molar volumes ${ }^{29}$ (Table 1$)$. The amplitude $F\left(q, R_{\mathrm{Sph}}\right)$ is

$F\left(q, R_{\mathrm{Sph}}\right)=\frac{4}{3} \pi R_{\mathrm{Sph}}^{3}\left(\rho_{\mathrm{CD}}-\rho_{\mathrm{S}}\right) \frac{3\left(\sin \left(q R_{\mathrm{Sph}}\right)-q R_{\mathrm{Sph}} \cos \left(q R_{\mathrm{Sph}}\right)\right)}{\left(q R_{\mathrm{Sph}}\right)^{3}}$

where $R_{\mathrm{Sph}}$ is the radius of the sphere equivalent to the $\mathrm{CD}, \rho_{\mathrm{CD}}$ and $\rho_{\mathrm{s}}$ are the scattering length densities of the cyclodextrin and solvent, respectively (Table 1 ). It has to be noted that the $\rho_{\mathrm{CD}}$ value was computed considering the number of exchangeable

Table 1 Scattering length density and molar volumes used in the data analysis $^{a}$

\begin{tabular}{lll}
\hline & $V_{\mathrm{i}}$ & $\rho$ \\
\hline $\mathrm{HP}-\alpha-\mathrm{CD}(\mathrm{DS}=0.6)$ & $7.91 \times 10^{-4}$ & $2.91 \times 10^{14}$ \\
$\mathrm{HP}-\beta-\mathrm{CD}(\mathrm{DS}=0.43)$ & $8.61 \times 10^{-4}$ & $3.08 \times 10^{14}$ \\
$\mathrm{HP}-\beta-\mathrm{CD}(\mathrm{DS}=0.8)$ & $9.94 \times 10^{-4}$ & $2.73 \times 10^{14}$ \\
$\mathrm{EO}$ & $3.67 \times 10^{-5}$ & $6.75 \times 10^{13}$ \\
$\mathrm{PO}$ & $5.38 \times 10^{-5}$ & $3.77 \times 10^{13}$ \\
$\mathrm{D}_{2} \mathrm{O}$ & $1.82 \times 10^{-5}$ & $6.36 \times 10^{14}$ \\
${ }^{a}$ Units are: $V_{\mathrm{i}}, \mathrm{m}^{3} \mathrm{~mol}^{-1} ; \rho, \mathrm{m}^{-2}$. & \\
\hline
\end{tabular}
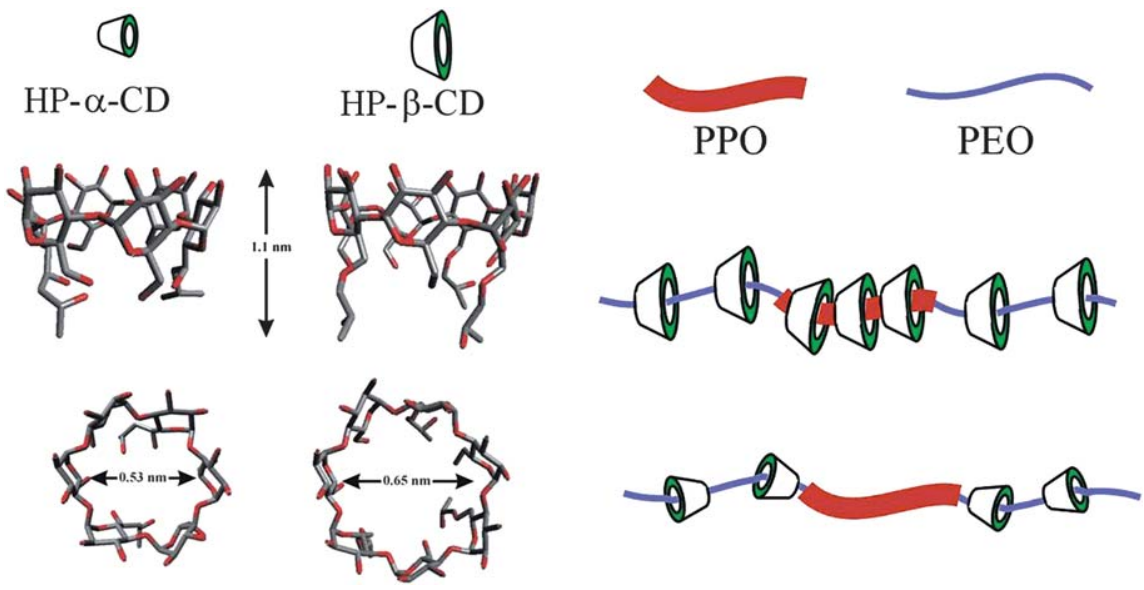

Fig. 1 Sketch representation of the threading behavior of PEO and PPO moieties into CDs with different cavity sizes. 
protons of the cyclodextrin, which is 18 for HP- $\alpha-C D$ and 21 for HP- $\beta$-CDs. The constant incoherent background was also taken into account as an additive constant $I_{\mathrm{bck}}$ in eqn (1). To verify whether the structure factor was eventually significant, two CD concentrations of 14 and $19 \mathrm{wt} \%$ were investigated. The fitting procedure was simultaneously applied to the two datasets taking into account the $\mathrm{CD}$ concentration values in the absolute intensity. A single fitting parameter $R_{\mathrm{Sph}}$ was obtained for the two concentrations and therefore one can conclude that for our experimental conditions the structure factor is negligible as well as the CD self-assembling process. In other words, the intensity scales with the concentration for a given CD. SASfit vers. 0.92.3 software was used for data analysis. ${ }^{30}$

\section{Copolymer solutions}

At the investigated concentrations of $25-46 \mathrm{wt} \%$ the micellar copolymer solutions in the absence and the presence of CD present a rather large scattering intensity and a strong correlation peak. All of the curves were well described by means of a model, extensively used for Pluronics in solution, which assumes polydisperse spheres with attached Gaussian chains ${ }^{31}$ that interact via a hard sphere potential. ${ }^{32}$ For such a model the scattering intensity is given by

$$
\begin{aligned}
I_{\mathrm{m}}(q)= & { }^{1} N \times P\left(q,\langle N\rangle, p, R_{\text {chain }}, d, \rho_{\mathrm{PO}}, \rho_{\mathrm{EO}}, \rho_{\mathrm{s}}\right) \\
& \times S\left(q, R_{\mathrm{hs}}\right)+I_{\mathrm{bck}}
\end{aligned}
$$

where ${ }^{1} N$ is the number density of particles related to the average aggregation number $(\langle N\rangle)$ and to the volume fraction of the aggregated matter $\left(\phi_{\text {agg }}\right)$ calculated by using the literature value for the unit molar volumes (Table 1). ${ }^{33}$ The form factor ${ }^{31}$ of the aggregate is $P\left(q,\langle N\rangle, p, R_{\text {chain }}, d, \rho_{\mathrm{PO}}, \rho_{\mathrm{EO}}, \rho_{\mathrm{s}}\right), R_{\text {chain }}$ being the radius of gyration of the attached chain, $\rho_{\mathrm{PO}}, \rho_{\mathrm{EO}}, \rho_{\mathrm{S}}$ are the scattering length densities (Table 1) of the core (PO), attached chain (EO) and $\mathrm{D}_{2} \mathrm{O}$, respectively. The center of mass of the attached Gaussian chains is located at $R_{\text {core }}+d R_{\text {chain, where }}$ $R_{\text {core }}$ is the average radius of the core and $d$ is a parameter accounting for the penetration of the Gaussian chains into the core being unitary if the penetration effect is negligible. The polydispersity, defined as $p=\left(\left\langle N^{2}\right\rangle /\langle N\rangle^{2}\right)-1$, is obtained using the Schulz distribution ${ }^{34}$ of the aggregation number. To reduce the number of fitting parameters for the water + copolymer + CD ternary system, both $d$ and $p$ were fixed and taken equal to the values in the absence of $C D$. This assumption is arbitrary as with the presence of $\mathrm{CD}$ the penetration into the core of threaded EO might substantially be modified and this applies similarly to $p$, especially if threading or interaction occurs with PO. On the other hand, it is necessary to reduce the number of coupled fit parameters in order to contain meaningful information; moreover the fitting procedure did not converge if $d$ and $p$ were also considered as free parameters.

For the structure factor $S(q)$ the hard sphere model in the Percus-Yevick approximation was employed, which only contains the hard sphere radius $\left(R_{\mathrm{hs}}\right)$ as a parameter. ${ }^{32}$

The contribution of dissolved single copolymer molecules can be considered by means of the Debye equation ${ }^{35}$ for a noninteracting random coil (eqn (4))

$$
I_{\mathrm{u}}(q)=\frac{c_{\mathrm{P}} M_{\mathrm{w}}}{N_{\mathrm{Av}} d_{\mathrm{p}}^{2}}\left(\rho_{\mathrm{p}}-\rho_{\mathrm{s}}\right)^{2} \frac{2}{x^{2}}\left(x-1+e^{-x}\right)+I_{\text {inc }}
$$

where $x$ is $\left(q R_{\mathrm{g}}\right),{ }^{2} c_{\mathrm{P}}$ is the free copolymer concentration $\left(\mathrm{g} \mathrm{cm}^{-3}\right)$, $M_{\mathrm{w}}$ is the copolymer molecular weight, $N_{\mathrm{Av}}$ the Avogadro number, $d_{\mathrm{p}}$ the density of the copolymer, ${ }^{33}$ whereas $\rho_{\mathrm{p}}$ is the scattering length density of the copolymer calculated from the scattering length density of each block (Table 1). In principle, $R_{\mathrm{g}}$ is the only fitting parameter in eqn (4) given that the free copolymer concentration is defined by the mass balance in the mixture. On the other hand, it is known that accurate values of $I_{\mathrm{u}}(q=0)$ can be calculated by means of eqn (4) only if the polymer is very dilute and overlapping effects are therefore negligible. For concentrated systems, the measured $I_{\mathrm{u}}(q=0)$ can be lower than those calculated from eqn (4) and $M_{\mathrm{w}}$ assumes a more general meaning of an effective molecular weight. To clarify this aspect, we compared $I_{\mathrm{u}}(q=0)$ as a function of $c_{\mathrm{P}}$ obtained from eqn (4) and compared with the experimental values by aqueous unimeric F68 solutions (see figure in the ESI $\dagger){ }^{36,37}$ It appears that the calculated values match the experimental ones only in the dilute regime while they deviate for even one order of magnitude at large concentrations. For this reason, in the fitting of the copolymer $+\mathrm{CD}+$ water ternary systems, $I_{\mathrm{u}}(q=0)$ was considered as a free parameter.

Finally, the scattering intensity was fitted by means of the following equation that assumes the additivity of the scattering contributions from each sub-unit

$$
I(q)=I_{\mathrm{m}}(q)+I_{\mathrm{u}}(q)+I_{\mathrm{CD}}(q)+I_{\mathrm{bck}}
$$

$I_{\text {bck }}$ being the constant incoherent scattering intensity. The success of the fitting procedure by using eqn (5) indicates that the interference cross-terms are negligible, this could be due to the very different size in the case of the micelle-unimer and micelle$\mathrm{CD}$ cross-terms, while for unimer-CD because the unimers are diluted. It has to be noted that the scattering contribution of the $\mathrm{CD}$ is entirely accounted for by $I_{\mathrm{CD}}(q)$ contribution, which is indeed calculated on the basis of the fitting results of the $\mathrm{CD}+$ $\mathrm{D}_{2} \mathrm{O}$ mixtures and the actual $\mathrm{CD}$ concentration in the ternary system. In an attempt to account for the CD threading into the aggregated PEO block, we included the CD into the scattering function of the attached Gaussian chain by considering its volume and the corresponding contrast obtained from the $\rho_{\mathrm{EO}}$ and $\rho_{\mathrm{CD}}$ values. We therefore assumed that $I_{\mathrm{CD}}(q)$ is null because the $\mathrm{CD}$ is completely located in the micelles' corona. Such a model was not successful because the high $q$ region was not properly taken into account by the fit (see figures in the ESI $\dagger$ ). Of course this is a limit case, actually it represents the opposite situation as given in eqn (5) where all of the CD is considered to contribute to the scattering intensity as the free $\mathrm{CD}$ in solution. However, based on that result, we do not exclude the CD threading into the corona of the micelles but state that the scattering feature of the single CD molecule is very much retained irrespective of whether it is threaded onto a polymer chain or free in solution.

\section{Results}

The SANS intensity curves were measured for a given copolymer micellar solution as a function of the cyclodextrin (CD) 
concentration. For a better and reliable comparison, experiments were also carried out on the copolymer + water and the CD + water mixtures, enabling us to interpret the observed data in terms of the specific interactions between the copolymer and $\mathrm{CD}$.

The cyclodextrins in $\mathrm{D}_{2} \mathrm{O}$ produced a quite low scattering intensity, which monotonically decreases with $q$ in the larger $q$ domain as expected for small particles (Fig. 2). The fitting procedure according to eqn (1) and (2) was successful (Fig. 2) and it provided effective radii of $0.903 \pm 0.005,0.890 \pm 0.005$, and $0.874 \pm 0.005 \mathrm{~nm}$ for HP- $\beta$-CD (degree of substitution, DS = 0.43 ), HP- $\beta-C D(D S=0.8)$ and HP- $\alpha-C D$, respectively. These results can hardly be compared with the actual radius and length of the CDs (Fig. 1) likely because the macrocycle is a hollow object that is here modelled as a compact sphere, on the other hand the obtained radii are similar to those reported ${ }^{21}$ for heptakis(2,6-di- $O$-methyl)- $\beta$-cyclodextrin from SANS data analysis $(0.9 \mathrm{~nm})$ and, as expected, they show a slightly smaller size for a $C D$ with the smaller cavity and almost a constant value if the substitution degree is varied.

As concerns the copolymer + water mixtures, the $I(q)$ vs. $q$ trends are typical ${ }^{31}$ for copolymer micelles strongly interacting with each others. Namely, for all the copolymers a strong correlation peak is observed (Fig. 3-5) being more pronounced

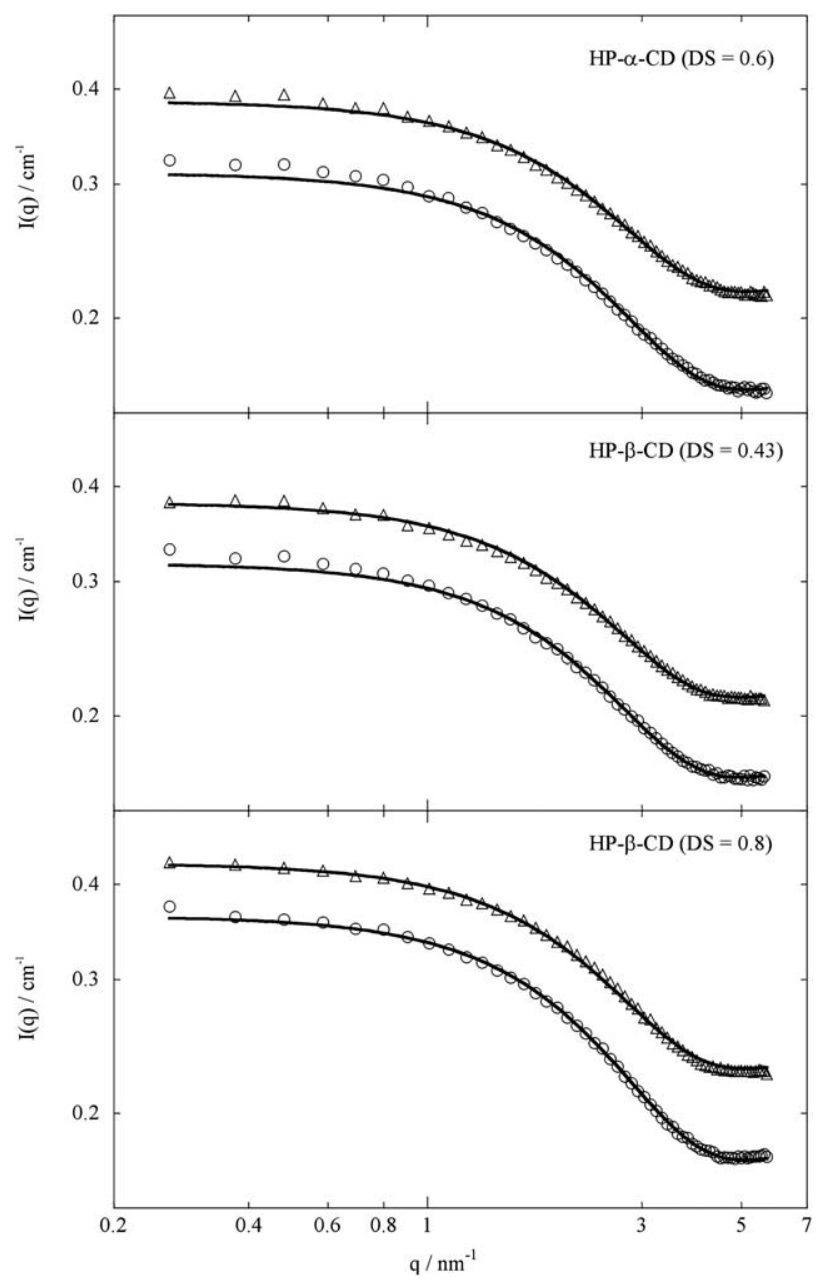

Fig. 2 SANS spectra of CD solutions in $\mathrm{D}_{2} \mathrm{O}$ at $14 \mathrm{wt} \%(\mathrm{O})$ and $19 \mathrm{wt} \%$ $(\triangle)$. Lines are best fits according to eqn (1) and (2).

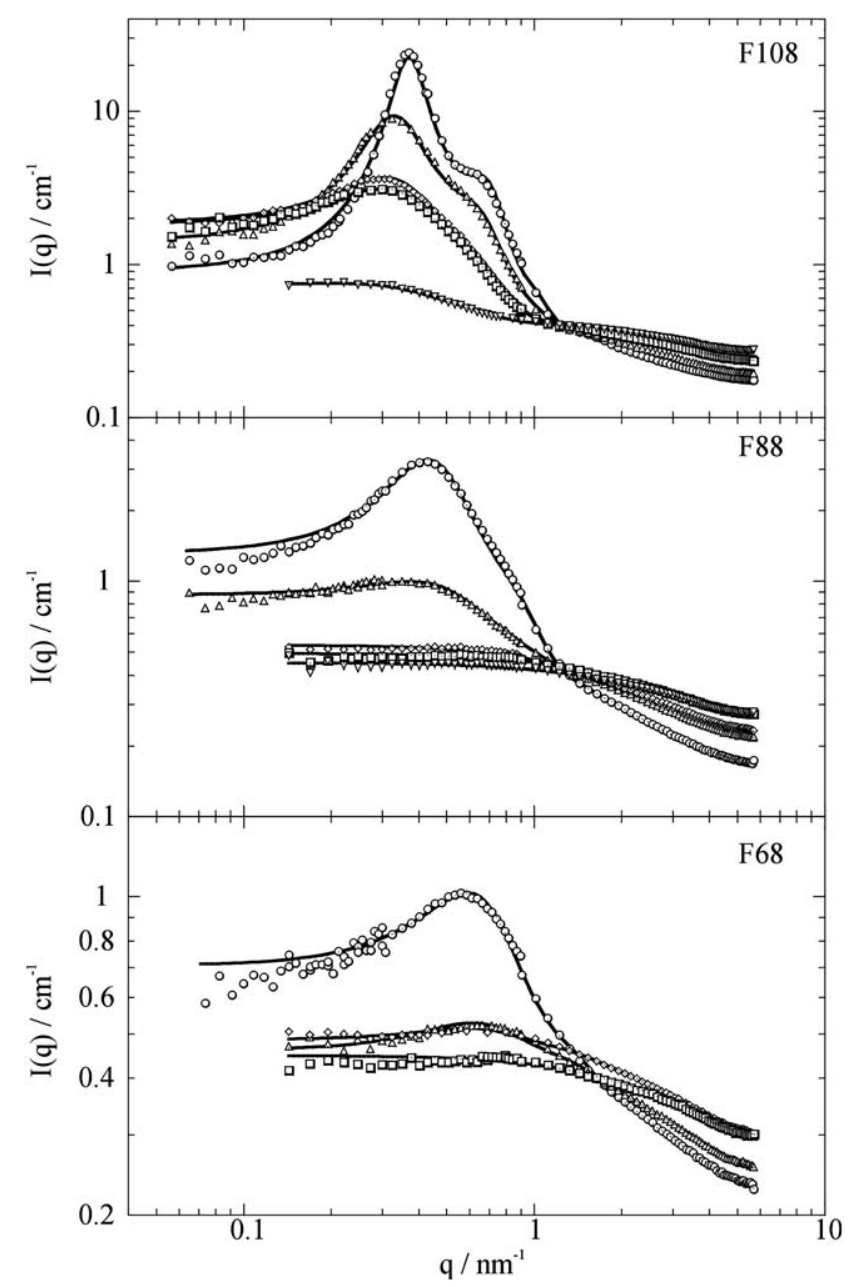

Fig. 3 SANS spectra of copolymers in $\mathrm{D}_{2} \mathrm{O}(\mathrm{O})$ and in the presence of HP- $\beta$-CD (DS = 0.43). The concentrations are F108 $0.018 \mathrm{~mol} \mathrm{~kg}^{-1}$ in the presence of $\mathrm{CD} 8.7(\triangle), 16.2(\diamond), 17.02(\square), 24.0(\square) \mathrm{wt} \%$; F88 $0.024 \mathrm{~mol} \mathrm{~kg}^{-1}$ in the presence of CD $5.6(\triangle), 8.1(\diamond), 17.7(\square), 23.8$ (ए) $\mathrm{wt} \%$; F68 $0.055 \mathrm{~mol} \mathrm{~kg}^{-1}$ in the presence of CD $6.3(\triangle), 9.2(\diamond), 18.5$ ( $\square$ ) $\mathrm{wt}_{\mathrm{t}} \%$. Lines are best fits according to eqn (5).

and shifted toward lower $q$ values with increasing length of the copolymer thereby indicating an increasing micellar size. As the copolymer concentration is $1.20,1.12$ and 2.13 times the critical micellar concentration (cmc) for F68, F88 and F108, respectively, one expects a larger concentration of bigger aggregates in the case of F108. The behaviour of PEO-PPO-PEO copolymers in water has been well investigated ${ }^{38-47}$ and, it is well-established that the values of the aggregation number are highly dependent on the copolymer molecular weight and this is similarly observed in our experiments (Table 2). In particular, the mean aggregation number $\langle N\rangle$ increases with the copolymer size and is very small for F68. Such a small value, in agreement with the literature one ${ }^{48}$ $(\langle N\rangle=7$ at $46 \mathrm{wt} \%$ of $\mathrm{F} 68$, which is slightly larger than the present concentration), indicates that $\mathrm{F} 68$ self-organizes with low cooperativity into loose clusters. Interestingly, we note that the penetration of the PEO chains into the core depends on the copolymer molecular weight. The $d$ parameter is $0.32,0.67$ and 1 for F108, F88 and F68, respectively, showing that in the Gaussian model the longer PEO chains penetrate more efficiently 


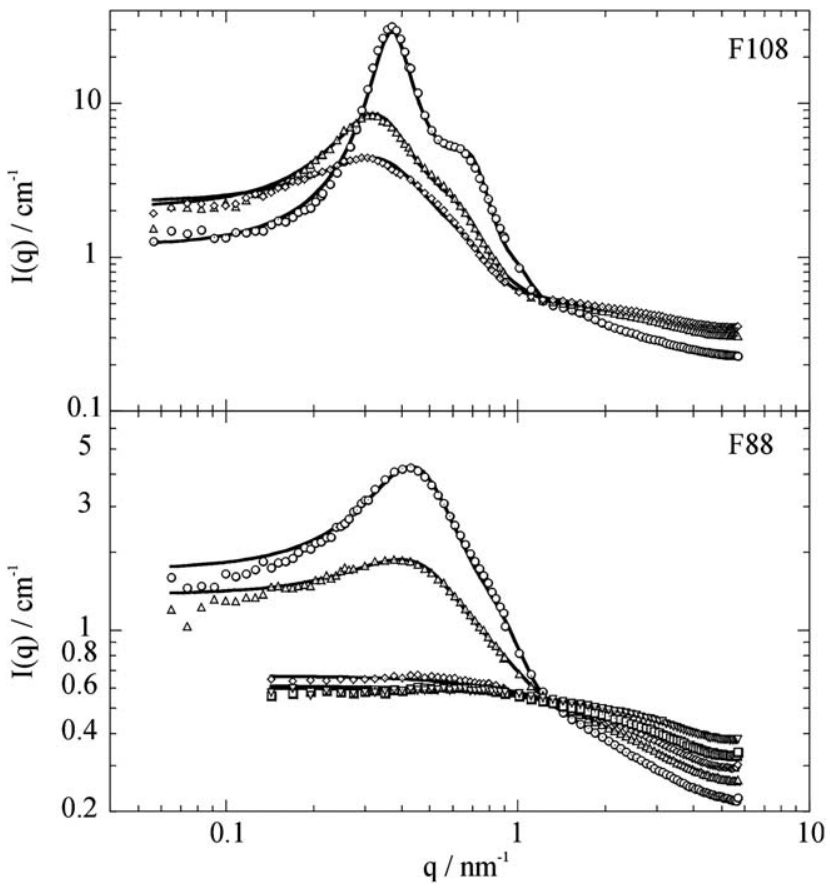

Fig. 4 SANS spectra of copolymers in $\mathrm{D}_{2} \mathrm{O}(\mathrm{O})$ and in the presence of HP- $\beta-C D$ (DS $=0.8$ ). The concentrations are F108 $0.018 \mathrm{~mol} \mathrm{~kg}^{-1}$ in the presence of CD $17.0(\triangle), 22.9(\diamond) \mathrm{wt} \%$; F88 $0.024 \mathrm{~mol} \mathrm{~kg}^{-1}$ in the presence of CD $5.8(\triangle), 11.0(\diamond), 18.5(\square), 23.4(\square) \mathrm{wt} \%$. Lines are best fits according to eqn (5).

into the micellar core and therefore needs a smaller $d$ correction parameter. This finding agrees with Monte Carlo simulations, which showed a negligible penetration if the core radius is larger than the gyration radius of the attached chain. ${ }^{31}$ Indeed, in the case of the F68 aggregates the correction for the penetration is not necessary.

The addition of $\mathrm{CD}$ to the copolymer solution generates effects strongly dependent on the CD cavity size and concentration and in general hardly dependent on the copolymer molecular weight. Namely, the addition of HP- $\beta-C D$ (DS $=0.43$ as well as DS $=$ 0.8 ) causes a destruction of the aggregates, easily followed by SANS (Fig. 3 and 4). In fact, the intensity as well as the peak is continuously reduced upon increasing the concentration of HP$\beta-\mathrm{CD}$ and for high $\mathrm{CD}$ content $(24 \mathrm{wt} \%$ ) the intensity indicates that the copolymer is basically in the unimeric state. The substitution degree for each glucopyranosidic unit in the CD does not play a very pronounced role (compare Fig. 3 and 4), but the reduction in micellization is somewhat stronger for the case of the less substituted HP- $\beta-C D$. This aspect is very clear by inspecting the fraction of micellized copolymer $\left(X_{\text {agg }}\right)$ as a function of the CD concentration (Fig. 6). $X_{\text {agg }}$ was calculated from the SANS analysis (eqn (5)) as the ratio between the aggregate volume fraction $\left(\phi_{\text {agg }}\right)$ and the stoichiometric copolymer volume fraction. It is straightforward that two kinds of interactions involved in the water + copolymer + HP- $\beta$-CD mixtures are in competition with each other: the forces controlling the copolymer/cyclodextrin inclusion complexes (polypseudorotaxanes) and those controlling the copolymer micelle formation. The destruction of the micelles induced by $\mathrm{CD}$ indicates that the formation of the polypseudorotaxanes is the favoured process.

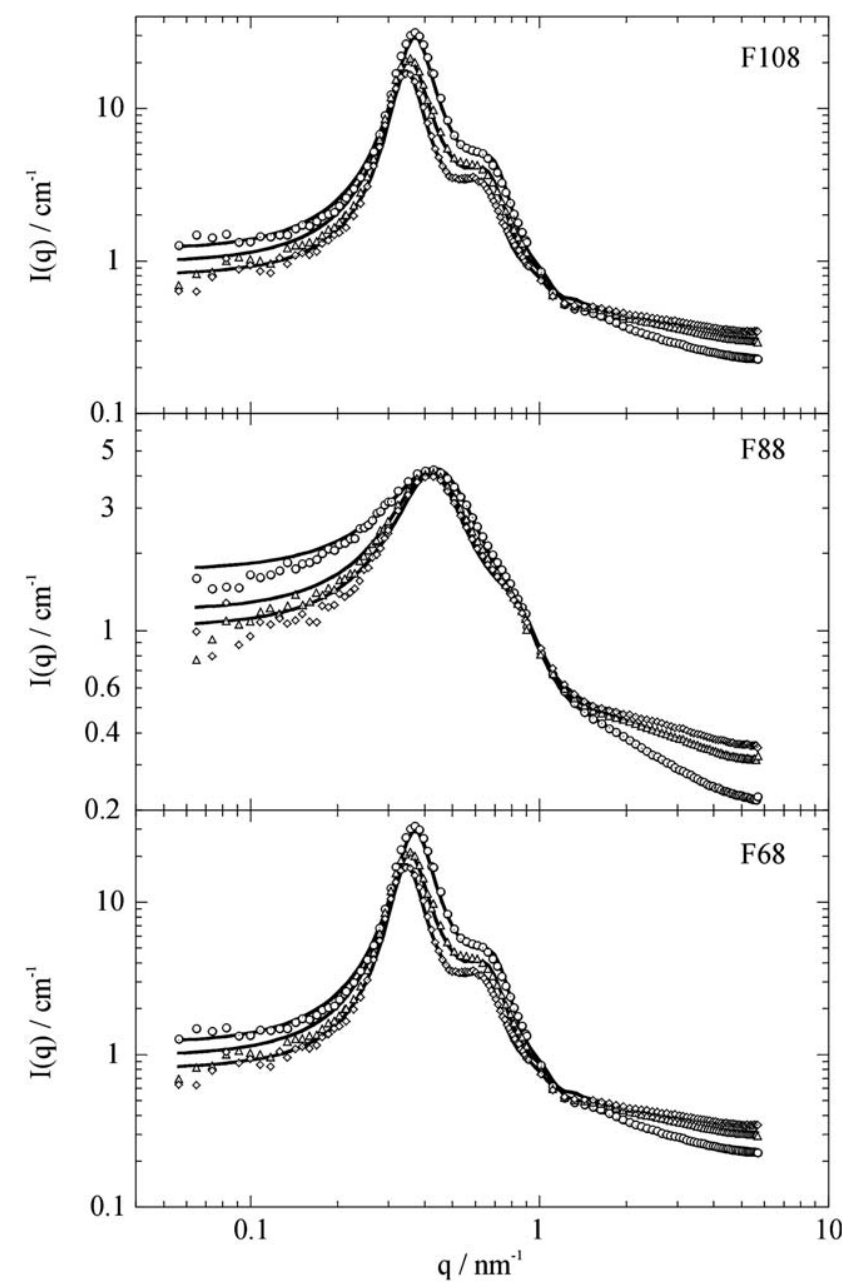

Fig. 5 SANS spectra of copolymers in $\mathrm{D}_{2} \mathrm{O}(\mathrm{O})$ and in the presence of $\mathrm{HP}-\alpha-\mathrm{CD}(\mathrm{DS}=0.6)$. The concentrations are F108 $0.018 \mathrm{~mol} \mathrm{~kg}^{-1}$ in the presence of $\mathrm{HP}-\alpha-\mathrm{CD}(\mathrm{DS}=0.6) 16.0(\triangle), 23.0(\diamond) \mathrm{wt} \%$; F88 $0.024 \mathrm{~mol} \mathrm{~kg}^{-1}$ in the presence of HP- $\alpha-\mathrm{CD}(\mathrm{DS}=0.6) 17.3(\triangle), 23.3(\diamond)$ $\mathrm{wt} \%$; F68 $0.055 \mathrm{~mol} \mathrm{~kg}^{-1}$ in the presence of HP- $\alpha$-CD (DS = 0.6) 16.4 $(\triangle), 25.9(\diamond) \mathrm{wt} \%$. Lines are best fits according to eqn $(5)$.

The CD apparently associates with the hydrophobic PPO domains, thereby rendering it much more hydrophilic and suppressing the tendency for micellization in a similar way as it would occur upon the addition of the surfactant. ${ }^{26,28}$

A different picture is observed for HP- $\alpha-C D$. By looking at the scattering curves for F108 (Fig. 5), one may argue that the disruptive action of HP- $\alpha-C D$ is weak, the peaks are only very slightly shifted to lower $q$ which implies that either there are fewer micelles or their size increases. In the case of F88 and F68 (Fig. 5), the peak position remains unchanged while the intensities at the maxima increase with HP- $\alpha$-CD addition to F68 (Fig. 5). Moreover, as a general feature, $X_{\text {agg }}$ increases upon the HP- $\alpha$-CD addition (Fig. 6) indicating that the micellization process is enhanced. As a general result, one may assess that at the highest $\mathrm{CD}$ composition investigated, the scattering pattern for the copolymer/HP- $\beta$-CD and copolymer/HP- $\alpha$-CD systems evidences highly different structural situations. It is also interesting to note that the micelle aggregation number $(\langle N\rangle)$ is not much altered by the $\mathrm{CD}$ addition (Table 2) and accordingly the 
Table 2 Aggregation number of copolymer micelles and fraction of copolymer in the inclusion complex ${ }^{a}$

\begin{tabular}{|c|c|c|c|c|}
\hline $\mathrm{CD}$ & $\mathrm{C}_{\mathrm{CD}}\left(\mathrm{wt}^{0} \%\right)$ & $\mathrm{CD} / \mathrm{PO}$ & $\langle N\rangle$ & $X_{\mathrm{cpx}}$ \\
\hline \multicolumn{5}{|l|}{ F88 } \\
\hline & 0 & 0 & $79 \pm 4$ & 0 \\
\hline $\mathrm{HP}-\beta-\mathrm{CD}(\mathrm{DS}=0.43)$ & 8.7 & 0.081 & $61 \pm 5$ & 0.17 \\
\hline $\mathrm{HP}-\beta-\mathrm{CD}(\mathrm{DS}=0.43)$ & 16.2 & 0.164 & $70 \pm 5$ & 0.34 \\
\hline $\mathrm{HP}-\beta-\mathrm{CD}(\mathrm{DS}=0.43)$ & 17.0 & 0.174 & $71 \pm 5$ & 0.37 \\
\hline $\mathrm{HP}-\beta-\mathrm{CD}(\mathrm{DS}=0.43)$ & 24.0 & 0.268 & $64 \pm 5$ & 0.48 \\
\hline$H P-\alpha-C D$ & 16.0 & 0.179 & $65 \pm 4$ & \\
\hline$H P-\alpha-C D$ & 23.0 & 0.281 & $60 \pm 5$ & \\
\hline HP- $\beta-\mathrm{CD}(\mathrm{DS}=0.8)$ & 17.0 & 0.156 & $68 \pm 5$ & \\
\hline $\mathrm{HP}-\beta-\mathrm{CD}(\mathrm{DS}=0.8)$ & 22.9 & 0.226 & $69 \pm 5$ & \\
\hline \multicolumn{5}{|l|}{ F88 } \\
\hline & 0 & 0 & $31 \pm 8$ & 0 \\
\hline $\mathrm{HP}-\beta-\mathrm{CD}(\mathrm{DS}=0.43)$ & 5.6 & 0.048 & $30 \pm 9$ & 0.055 \\
\hline $\mathrm{HP}-\beta-\mathrm{CD}(\mathrm{DS}=0.43)$ & 8.1 & 0.072 & & 0.078 \\
\hline $\mathrm{HP}-\beta-\mathrm{CD}(\mathrm{DS}=0.43)$ & 16.3 & 0.162 & & 0.16 \\
\hline HP- $\beta-C D(D S=0.43)$ & 23.8 & 0.255 & & 0.20 \\
\hline $\mathrm{HP}-\alpha-\mathrm{CD}$ & 17.3 & 0.189 & $28 \pm 9$ & \\
\hline $\mathrm{HP}-\alpha-\mathrm{CD}$ & 23.4 & 0.276 & $25 \pm 9$ & \\
\hline HP- $\beta-C D(D S=0.8)$ & 5.8 & 0.045 & $28 \pm 8$ & \\
\hline $\mathrm{HP}-\beta-\mathrm{CD}(\mathrm{DS}=0.8)$ & 11.0 & 0.091 & & \\
\hline $\mathrm{HP}-\beta-\mathrm{CD}(\mathrm{DS}=0.8)$ & 18.5 & 0.166 & & \\
\hline $\mathrm{HP}-\beta-\mathrm{CD}(\mathrm{DS}=0.8)$ & 23.4 & 0.224 & & \\
\hline \multicolumn{5}{|l|}{ F68 } \\
\hline $\mathrm{HP}-\beta-\mathrm{CD}(\mathrm{DS}=0.43)$ & 6.3 & 0.032 & $3.1 \pm 0.3$ & 0.060 \\
\hline $\mathrm{HP}-\beta-\mathrm{CD}(\mathrm{DS}=0.43)$ & 9.2 & 0.049 & $2.7 \pm 0.3$ & 0.067 \\
\hline $\mathrm{HP}-\beta-\mathrm{CD}(\mathrm{DS}=0.43)$ & 18.5 & 0.109 & & 0.11 \\
\hline$H P-\alpha-C D$ & 16.4 & 0.104 & $8 \pm 1$ & \\
\hline $\mathrm{HP}-\alpha-\mathrm{CD}$ & 25.9 & 0.185 & $9 \pm 1$ & \\
\hline
\end{tabular}

${ }^{a}$ The polydispersity $\left(\left\langle N^{2}\right\rangle\left\langle\langle N\rangle^{2}-1\right)\right.$ obtained from the Schulz distribution of the aggregation number is $0.80 \pm 0.02,0.55 \pm 0.09$ and $0.12 \pm 0.08$ for F108, F88 and F68, respectively. CD/PO is a mole ratio. The average aggregation number is weighted by volume. $X_{\mathrm{cpx}}$ is the fraction of copolymer in the inclusion complexes calculated by means of eqn (8) for the systems for which the equilibrium constant is available.

hard sphere radius hardly changes as well (Fig. 7). As the copolymers have the same chemical structure and hydrophilic/ hydrophobic ratio and differ only in the molecular weight, one expects that the different scattering behaviour observed for the different types of CDs is ascribable to the mechanism of action of CDs on the various polymer blocks. In particular, the specific response of the copolymer aggregates to the two CDs reflects the $\mathrm{CD}$ selectivity toward the EO and the PO units. The ability of HP- $\beta-C D$ to include both the EO and the PO segments renders the polymer much more hydrophilic (by threading onto the hydrophobic PO units) and thereby suppresses the formation of aggregates. In the case of HP- $\alpha-\mathrm{CD}$, only the EO segments can be included and the complexed copolymer may participate to the formation of micelles having the hydrophilic shells decorated with the CD baskets. Such a picture explains the more pronounced maximum detected for $\mathrm{F} 68$ due to the stronger interactions expected for aggregates with "HP- $\alpha$-CD decorated corona", i.e., a higher effective hard sphere volume fraction. Furthermore the F68 forms the smallest micelles and has the weakest tendency for aggregation; accordingly it is most easily influenced by the HP- $\alpha$-CD modification.

As stated earlier, in the fitting procedure it was necessary to take into account the scattering of the unimers in solution. This

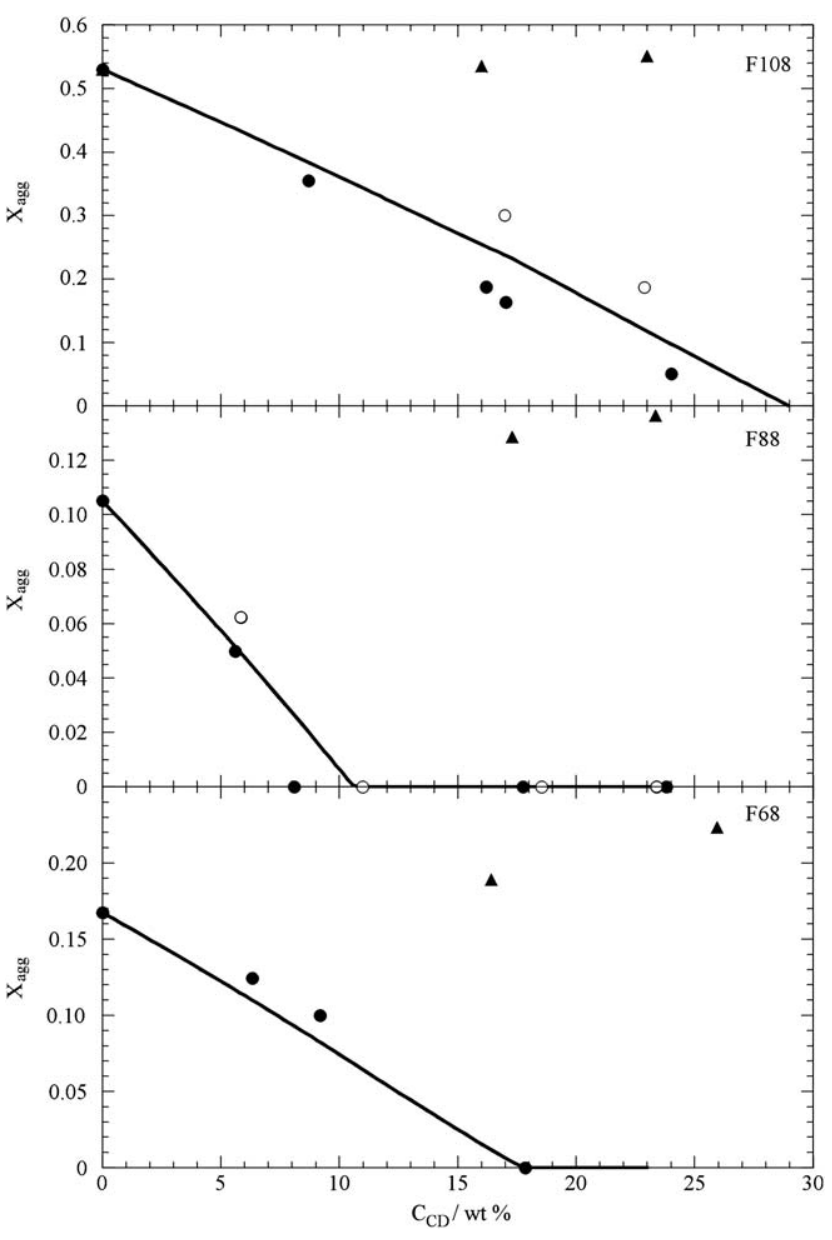

Fig. 6 Fraction of micellized copolymer as a function of the HP- $\alpha-C D$ $(\boldsymbol{\Delta}), \mathrm{HP}-\beta-\mathrm{CD}$ DS $=0.43(\bullet)$ and HP- $\beta-\mathrm{CD}$ DS $=0.8(\mathrm{O})$ concentration. Lines are calculated according to eqn (6)-(8).

contribution was negligible for $\mathrm{F} 108$, with its lower $\mathrm{cmc}$ value and correspondingly larger tendency to form aggregates, but necessary for F88 and F68. The radius of gyration $\left(R_{\mathrm{g}}\right)$ and the $I_{\mathrm{u}}(q=0)$ fitting parameters are displayed in Fig. 8. $R_{\mathrm{g}}$ hardly changes with the $\mathrm{CD}$ concentration, whereas $I_{\mathrm{u}}(q=0)$ does. As we clearly demonstrated, the addition of HP- $\beta$-CD leads to rupturing of the micellar aggregates; on the basis of this, one would expect an increase in the unimer contribution to the scattering intensity upon addition of HP- $\beta$-CD. Surprisingly, an opposite result is obtained for both, F88 and F68, in the presence of the two HP- $\beta$-CDs (Fig. 8). For a correct interpretation of $I_{\mathrm{u}}(q=0)$ one has to consider that we are far from a dilute system and therefore the overlapping effects should be significant as discussed in the next paragraph.

\section{Discussion}

\section{Effect of HP- $\beta$-CDs on the aggregated copolymer}

The $X_{\text {agg }}$ decrease upon the HP- $\beta$-CD addition can be interpreted in terms of an increase in the critical micellar concentration of the copolymer in the mixture with $\mathrm{CD}\left(\mathrm{cmc}^{*}\right)$, i.e., the presence of the $\mathrm{CD}$ renders the Pluronics more hydrophilic. This effect is well 


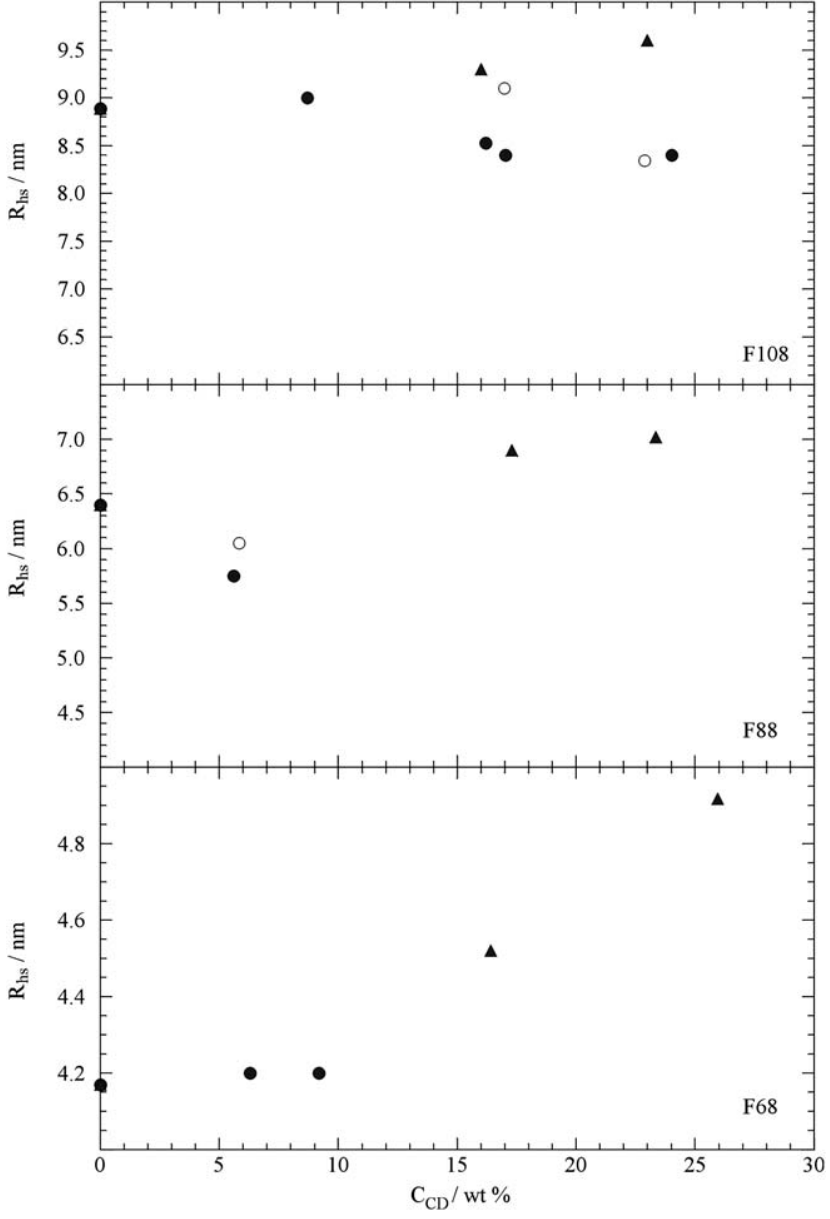

Fig. 7 Hard sphere radius for the copolymer micelles as a function of the $\mathrm{HP}-\alpha-\mathrm{CD}(\boldsymbol{\Delta}), \mathrm{HP}-\beta-\mathrm{CD}$ DS $=0.43(\bullet)$ and HP- $\beta-\mathrm{CD}$ DS $=0.8(\bigcirc)$ concentration.

known for conventional surfactants ${ }^{49,50}$ incorporated into the cyclodextrin cavity and, as for the ternary water + cyclodextrin + surfactant systems ${ }^{\mathbf{4 9 , 5 1 , 5 2}}$ the apparent critical micellar concentration $\left(\mathrm{cmc}^{*}\right)$ can be defined as

$$
\mathrm{cmc}^{*}=\mathrm{cmc}+C_{\mathrm{cpx}}
$$

where $\mathrm{cmc}$ is the critical micellar concentration of the copolymer in water in the absence of $\mathrm{CD}$ and $C_{\mathrm{cpx}}$ is the concentration of the copolymer involved in the inclusion complex. According to eqn (6), once the non-complexed monomer concentration in the presence of $\mathrm{CD}$ reaches the $\mathrm{cmc}$ value micellization takes place. To verify whether eqn (6) is valid also for our systems, we calculated $X_{\text {agg }}$ as $\left(C_{\mathrm{P}}-\mathrm{cmc}^{*}\right) / C_{\mathrm{P}}, C_{\mathrm{P}}$ being the stoichiometric copolymer concentration. Both the equilibrium constant for the CD-copolymer inclusion complex formation and the stoichiometry of the complex being known for HP- $\beta-C D(D S=0.43),{ }^{10}$ we were able to calculate $C_{\mathrm{cpx}}$ for all the inclusion complexes.

By assuming that the copolymer is composed of a certain number of sites $(z)$ each one interacting with one CD molecule, the following equations for the equilibrium constant $\left(K_{1}\right)$ and the copolymer mass balance were derived

$$
K_{1}=x_{1} /\left[C_{\mathrm{P}, \mathrm{w}}\left(1-x_{1}\right)\right] \text { and } C_{\mathrm{P}}=C_{\mathrm{P}, \mathrm{w}}+x_{1} C_{\mathrm{CD}} / z
$$

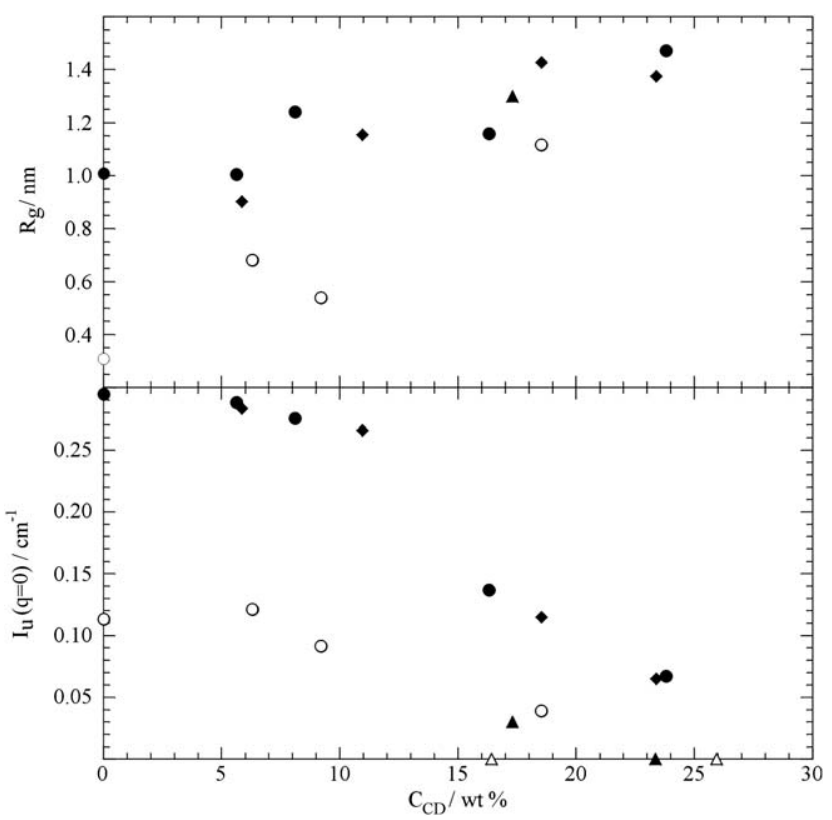

Fig. $8 R_{\mathrm{g}}$ and $I_{\mathrm{u}}(q=0)$ values for F88 (filled symbols) and F68 (empty symbols) as functions of concentration of the HP- $\alpha$-CD (triangles), HP$\beta-C D$ DS $=0.43$ (circles) and HP- $\beta-C D$ DS $=0.8$ (diamonds).

where $x_{1}$ is the fraction of the $\mathrm{CD}$ involved in the one-to-one binding, $C_{\mathrm{CD}}$ the stoichiometric $\mathrm{CD}$ concentration, and $C_{\mathrm{P}, \mathrm{w}}$ is the copolymer concentration in the aqueous phase. Note that $z$ represents the maximum number of $\mathrm{CD}$ molecules that can thread one copolymer molecule. By combining $K_{1}$ and the copolymer mass balance one obtains

$$
\begin{aligned}
& X_{1}=\frac{K_{1} C_{\mathrm{CD}} / Z+K_{1} C_{\mathrm{p}}+1}{2 K_{1} C_{\mathrm{CD}} / Z}+ \\
& -\frac{\sqrt{\left(K_{1} C_{\mathrm{CD}} / Z\right)^{2}+2 K_{1} C_{\mathrm{CD}}\left(1-K_{1} C_{\mathrm{P}}\right) / Z+\left(K_{1} C_{\mathrm{P}}\right)^{2}+2 K_{1} C_{\mathrm{P}}+1}}{2 K_{1} C_{\mathrm{CD}} / Z}
\end{aligned}
$$

and therefore $C_{\mathrm{cpx}}$ is obtained from the $x_{1} C_{\mathrm{CD}}$ product. Details of the calculation and assumptions are given in the ESI $\uparrow$. The cmc values were taken from the literature. ${ }^{33}$

Data in Fig. 6 show that there is a satisfactory agreement between the experimental $X_{\text {agg }}$ and the calculated values. This result confirms the competition between copolymer self-assembly and CD-copolymer inclusion complex formation, thereby allowing to fine-tune micelle formation through the $\mathrm{CD}$ amount. In fact, as shown in Fig. 6, there exists a critical CD concentration $\left(C_{\mathrm{CD}}{ }^{*}\right)$, specific to the copolymer molecular weight, above which self-assembled structures are no more present, as observed in the SANS experiments. Going further, for the copolymer/HP$\beta-\mathrm{CD}(\mathrm{DS}=0.43)$ mixtures, we observed a linear correlation between the $C_{\mathrm{CD}} * / C_{\mathrm{P}}$ weight ratio and the $X_{\mathrm{agg}}$ values in water (Fig. 9). The slope $\left(s=\delta\left(C_{\mathrm{CD}} * / C_{\mathrm{P}}\right) / \delta X_{\text {agg }}\right)$ of such a straight line provides the number of $\mathrm{CD}$ moles necessary to break down $1 \mathrm{~mol}$ of self-assembled copolymer given by $s M_{\mathrm{wP}} / M_{\mathrm{wCD}}$, where $M_{\mathrm{wP}}$ and $M_{\mathrm{wCD}}$ are the copolymer and $\mathrm{CD}$ molecular weight, respectively. By considering the number of $\mathrm{EO}$ and $\mathrm{PO}$ units in a copolymer chain, it is observed that one HP- $\beta-C D$ molecule is threaded along $c a$. $11 \mathrm{EO}$ and/or PO units of the copolymer 


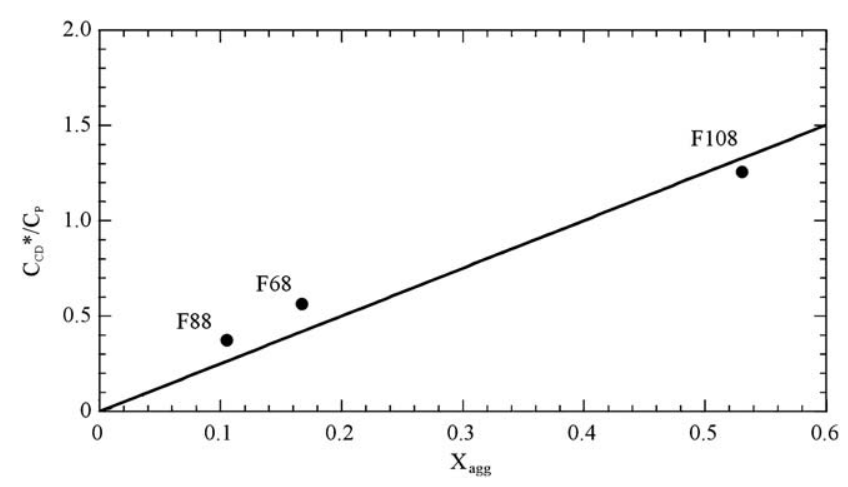

Fig. 9 Weight ratio between HP- $\beta-C D(D S=0.43)$ and copolymer corresponding to the complete micelles rupturing as a function of the fraction of micellized copolymer in $\mathrm{D}_{2} \mathrm{O}$. Line is the best linear fit.

chain. It is interesting that such a stoichiometry corresponds to the maximum number of $\mathrm{CD}$ molecules that one copolymer molecule can thread. ${ }^{10}$ This result is particularly relevant to applications where a controlled release of compounds contained in micelles is required.

Increasing the hydrophobic modification of HP- $\beta$-CD generates a slightly less pronounced decrease in $X_{\text {agg }}$ upon CD addition (Fig. 6). It is known that the hydroxypropyl-groups in the CDs disfavour the interaction between adjacent $C D$ rings threaded onto a polymer chain ${ }^{10,53}$ and consequently the number of HP-CD molecules per polymer chain is in general smaller than that obtained for the corresponding native CDs. ${ }^{10}$ Similarly, the clusters of native $\mathrm{CD}$ present in water practically disappear if the corresponding HP-CDs are considered. ${ }^{54}$ To the light of these insights, one can assess that the HP- $\beta$-CD with DS $=0.8$ likely possesses a lower tendency to include the copolymer and therefore it disturbs the copolymer self-assembled to a lesser extent than HP- $\beta$-CD with DS $=0.43$, as seen when comparing Fig. 3 and 4 (see also Table 2).

Micelle formation is the result of the delicate balance of opposite forces: (1) the attractive interactions between the apolar PO moieties, which tend to minimize the contact with water and (2) the repulsive interactions between the hydrophilic parts, which tend to maximize the contact with water. The presence of polypseudorotaxanes in our systems, even in large amounts (Table 2), does not modify both the equilibrium of interactions and the concentration of free copolymer at which the micellization takes place (as the calculated $X_{\text {agg }}$ data demonstrate) leading to micelles with unchanged size. Thus, for variation in $X_{\mathrm{agg}}$ of $c a$. one order of magnitude observed for all the copolymers, the aggregation number remains constant. This means that the $\mathrm{CD}$ acts as a masking agent of the copolymer decreasing the chemical potential of the unimers in the aqueous phase due to the inclusion complexes' formation but it does not alter the solvent properties because of the highly hydrophilic nature of the polypseudorotaxanes. This also explains why $R_{\mathrm{hs}}$ is essentially independent of the CD concentration. Similar results were obtained for micelles of fluorinated and hydrogenated surfactants in the presence of HP- $\beta$-CD the thermodynamic properties of which remained unchanged upon the macrocycle addition..$^{29,50}$ On the other hand, for a correct interpretation of the results, one should also consider that the Pluronics are indeed quite polydisperse, especially with respect to their hydrophilic/hydrophobic balance, and that an enrichment of the most hydrophobic moieties into the micelles was proven by NMR. ${ }^{55}$ Therefore one may argue that the $\mathrm{CD}$ is able to incorporate the more hydrophilic copolymer, which is loosely aggregated into the micelles, generating a decrease in the aggregated copolymer that is more hydrophobic. The effect of the lower micelle concentration and the increased hydrophobicity compensate each other and therefore $\langle N\rangle$ is constant.

\section{Effect of HP- $\alpha-\mathrm{CD}$ on the aggregated copolymer}

A rather different situation arises when HP- $\beta-C D$ is replaced by HP- $\alpha-C D$, which generates a $X_{\text {agg }}$ increase indicating that the micellization process is enhanced. Such an effect opposite to that generated by HP- $\beta$-CD is usually observed for solutes incorporating into the Pluronics micelles. ${ }^{56-58}$ Accordingly, the larger binding constants to the micelles correspond to the lower critical micellar concentration. For our systems, this situation should be ruled out because HP- $\alpha-\mathrm{CD}$ cannot be encapsulated into the copolymer micelles due to its highly hydrophilic character. Nevertheless, based on the selectivity of HP- $\alpha-C D$, which threads EO but not PO, one may speculate the presence of a cooperative process, involving free copolymer and complexed copolymer molecules, which leads to the formation of copolymer micelles with a core composed of PPO blocks and a corona of EO units "decorated" with HP- $\alpha-C D$. We have previously demonstrated ${ }^{10}$ that, at infinite CD concentration, one HP- $\alpha-\mathrm{CD}$ molecule is located in every $c a$. 11 EO units along a PEO chain. The corresponding native $\alpha-\mathrm{CD}$ threads the PEO in the most compact way being $2 \mathrm{EO}$ units for each $\alpha-\mathrm{CD}$ under the same conditions. The consequence of this different stoichiometry is ascribable to the presence of head-to-head interactions of $\alpha-\mathrm{CD}$, which are absent in the case of HP- $\alpha-\mathrm{CD}$; as a result, the Pluronic/ $\alpha-\mathrm{CD}$ complex is sparingly soluble in water while the Pluronic/HP- $\alpha-\mathrm{CD}$ complex is rather soluble. The low stoichiometry of the inclusion complexes does not create constraints to the copolymer molecule, which essentially maintains comparable features than those of the free molecules. For these reasons, the inclusion complexes participate to the formation of micelles and the potential changes of the hydration state of the copolymer do not alter the size of these structures. The slight increase in $R_{\mathrm{hs}}$ (Fig. 7) is a measure of the enhanced interactions consistent with the above findings and is due to a bulkier corona containing the threaded HP- $\alpha-C D$.

One may conclude that in the presence of $\mathrm{HP}-\alpha-\mathrm{CD}$, the micellar size does not change significantly, while the micelle concentration slightly increases.

\section{Effect of HP-CDs on the non-self-assembled copolymer}

Finally, the $I_{\mathrm{u}}(q=0)$ data deserve some comments. One would expect an increase in $I_{\mathrm{u}}(q=0)$ upon addition of HP- $\beta-\mathrm{CD}$ because both the concentration of free copolymer and the molecular mass of the scattering objects (complexed unimers) increase. Surprisingly, an opposite result is obtained for $I_{\mathrm{u}}(q=0)$ in all of the investigated systems (Fig. 8). A reasonable explanation of this finding can be given by assuming that overlapping effects between pseudopolyrotaxanes are even more significant than for free unimers in water below the cmc. The steric constraints present in the pseudopolyrotaxanes generate a less 
compact coil configuration as the increasing gyration radius $\left(R_{\mathrm{g}}\right)$ vs. $C_{\mathrm{CD}}$ trends show (Fig. 8). Therefore, the larger concentration of non-self-assembled copolymer (even larger than the $\mathrm{cmc}$ ) and an increasing $R_{\mathrm{g}}$ value are responsible for more pronounced overlapping effects, which then lead to a decrease in $I_{\mathrm{u}}(q=0)$. Moreover, based on the scattering length densities (Table 1), one has to consider that the CD threading onto the polymer chain generates a decrease in contrast between the solvent and the pseudopolyrotaxanes with respect of that between the solvent and the unimer and it should also be noted that the scattering of the $\mathrm{CD}$ moieties was accounted for separately in eqn (5). It is intriguing to observe that the addition of HP- $\alpha$-CD to F68 and F88 also causes a pronounced decrease in $I_{\mathrm{u}}(q=0)$ (Fig. 8) although the self-assembled copolymer aggregates' concentration is only weakly influenced. Keeping in mind that HP- $\alpha-C D$ threads the PEO moiety of the copolymer, this finding can be explained by the fact that the PEO unit is much larger than the PPO block and accordingly the effect on $R_{\mathrm{g}}$ should be more pronounced (as also indicated in Fig. 8).

\section{Conclusions}

We show that the SANS technique is a powerful tool to evidence the key parameters controlling the formation of supramolecular assemblies in mixtures of CDs and amphiphilic Pluronic copolymers. In that context the CD cavity size is fundamental. HP- $\beta$-CDs lead to a break-down of the copolymer micelles, the concentration of which is a linearly decreasing function of the HP- $\beta-C D$ concentration, but it does not alter the micellar size. Increasing the degree of substitution of the HP- $\beta-C D$ makes the CD slightly less efficient in disturbing the copolymer selfassembled but retaining the general behaviour. This phenomenon was clearly described by a simple thermodynamic model which provides a tool to predict the experimental conditions under which total or partial micelle rupturing will take place. Accordingly the aggregation behaviour in these mixtures can be finely tuned in a quantitative matter. For such a prediction, the key parameters are the $\mathrm{CD} /$ copolymer stoichiometry and the micelle concentration in water. This aspect is very relevant with respect to the controlled release of compounds contained in such micelles.

A completely different situation is observed when adding HP$\alpha-C D$, which does neither affect the micelle concentrations nor their aggregation number. Nonetheless aggregates with a PPO core and a PEO corona decorated with the CD baskets are formed, as evidenced from larger hard sphere repulsion observed for this case. This is due to the fact that HP- $\alpha-C D$ can only thread onto the PEO chains, thereby only decorating the existing micelles but not altering the tendency for micelle formation, as that is driven by the hydrophobic PO part of the Pluronic molecules. ${ }^{25,28}$

These complex supramolecular structures can open the way to new smart stimuli- and thermo-sensitive materials for specific applications. A sketch representation of the CD/copolymer mechanism of interaction is given in Fig. 10.

\section{Materials and methods}

\section{Chemicals}

The block copolymers $\mathrm{EO}_{76} \mathrm{PO}_{29} \mathrm{EO}_{76}(\mathrm{~F} 68$, average molecular weight $\left.M_{\mathrm{w}}=8350 \mathrm{~g} \mathrm{~mol}^{-1}\right), \mathrm{EO}_{103} \mathrm{PO}_{39} \mathrm{EO}_{103}$ (F88, average molecular weight $M_{\mathrm{w}}=11400 \mathrm{~g} \mathrm{~mol}^{-1}$ ) and $\mathrm{EO}_{132} \mathrm{PO}_{50} \mathrm{EO}_{132}$ (F108, average molecular weight $M_{\mathrm{w}}=14600 \mathrm{~g} \mathrm{~mol}^{-1}$ ) were gifts from BASF. $\mathrm{D}_{2} \mathrm{O}$ was purchased from Eurisotop in $99.9 \%$ isotopic purity. Hydroxypropyl- $\beta$-cyclodextrin (HP- $\beta$-CD) with an average substitution degree for each glucopyranosidic unit (DS) of 0.43 was from Acros. HP- $\beta$-CD with DS $=0.8$ and hydroxypropyl- $\alpha$-cyclodextrin (HP- $\alpha$-CD) having DS $=0.6$ are Aldrich products. The water content of the cyclodextrins was determined by thermo-gravimetric analysis and it is 9.8, 14.7 and $15.0 \mathrm{wt} \%$ for HP- $\alpha-C D$, HP- $\beta-C D(D S=0.43)$ and HP- $\beta-C D$ (DS $=0.8)$, respectively. All the chemicals were used as received.

\section{Small angle neutron scattering}

The small-angle neutron scattering (SANS) experiments were performed at the Helmholtz-Zentrum-Berlin (Germany) on the instrument $\mathrm{V} 4 .^{59} \mathrm{~A}$ wavelength of $6.0 \AA$ (fwhm 10\%) was selected. The sample to detector (and in parenthesis collimation) distances were chosen as $1 \mathrm{~m}(2 \mathrm{~m}), 4 \mathrm{~m}(4 \mathrm{~m})$ and $12 \mathrm{~m}(12 \mathrm{~m})$ in order to cover the 0.05 to $6 \mathrm{~nm}^{-1}$ range of the scattering vector (q). The data were registered on a $64 \times 64 \mathrm{~cm}^{2}$ two-dimensional detector. Data reduction was performed on 2D patterns using BerSANS; ${ }^{60}$ data were corrected for the detector efficiency using the scattering by $1 \mathrm{~mm} \mathrm{H}_{2} \mathrm{O}$ and the contribution from the empty cell was subtracted. Absolute scale was obtained using the intensity of water; all corrected patterns being isotropic were radially averaged, and data from different configurations were merged without the assistance of arbitrary coefficients. It should be noted that the incoherent scattering, resulting essentially from

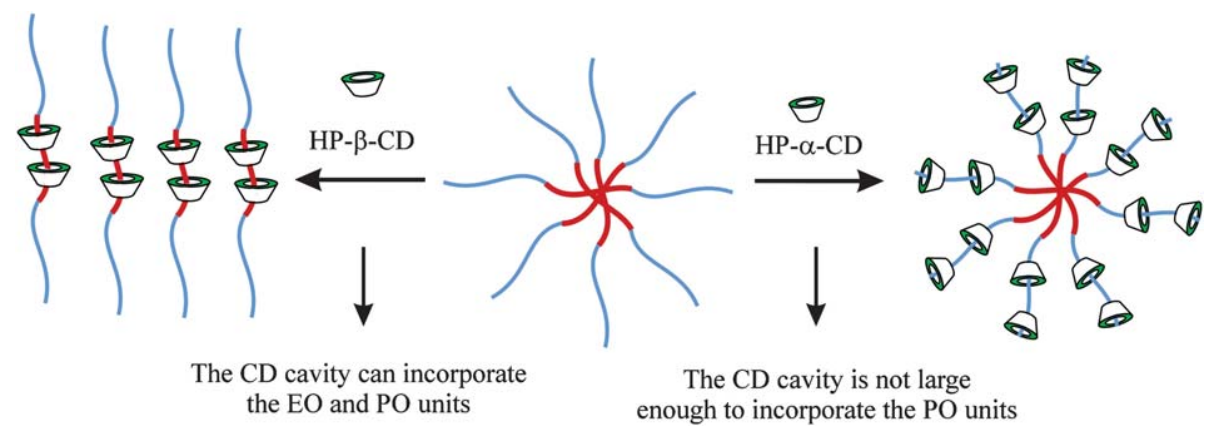

Fig. 10 Sketch representation of the mechanism of interaction between Pluronics micelles and CDs with different cavity sizes. 
the presence of hydrogen in the samples, was not subtracted from the intensity curves. All samples were prepared in $\mathrm{D}_{2} \mathrm{O}$ to increase the contrast with the hydrogenated material and to reduce the incoherent background. Samples were thermostatted at $25.0 \pm 0.1^{\circ} \mathrm{C}$.

\section{Acknowledgements}

The work was financially supported by the University of Palermo (Italy) and Bando CORI 2008. The SANS measurements of this research project have been supported by the European Commission under the 7th Framework Programme through the Key Action: Strengthening the European Research Area, Research Infrastructures. Contract no.: 226507 (NMI3) and we thank the HZB for providing the corresponding SANS beam time.

\section{References}

1 G. Wenz and B. Keller, Angew. Chem., Int. Ed., 1992, 31, 197-199.

2 S. A. Nepogodiev and J. F. Stoddart, Chem. Rev., 1998, 98, 1959 1976.

3 F. H. Huang and H. W. Gibson, Prog. Polym. Sci., 2005, 30, 982-1018.

4 C. Gaeta, M. O. Vysotsky, A. Bogdan and V. Böhmer, J. Am. Chem. Soc., 2005, 127, 13136-13137.

5 M. Horie, Y. Suzaki and K. Osakada, Inorg. Chem., 2005, 44, 58445853.

6 J. W. Lee, S. Samal, N. Selvapalam, H. J. Kim and K. Kim, Acc. Chem. Res., 2003, 36, 621-630.

7 A. Harada and M. Kamachi, Macromolecules, 1990, 23, 2821-2823.

8 T. E. Girardeau, T. Zhao, J. Leisen, H. W. Beckham and D. G. Bucknall, Macromolecules, 2005, 38, 2261-2270.

9 L. Chen, X. Zhu, D. Yan, Y. Chen, Q. Chen and Y. Yao, Angew. Chem., Int. Ed., 2006, 45, 87-90.

10 G. Lazzara and S. Milioto, J. Phys. Chem. B, 2008, 12, 11887-11895.

11 P. Lo Nostro, L. Giustini, E. Fratini, B. W. Ninham, F. Ridi and P. Baglioni, J. Phys. Chem. B, 2008, 112, 1071-1081.

12 F. Yuen and K. C. Tam, Soft Matter, 2010, 6, 4613-4630.

13 A. Guerrero-Martínez, D. Ávila, F. J. Martínez-Casado, J. A. Ripmeester, G. D. Enright, L. De Cola and G. Tardajos, J. Phys. Chem. B, 2010, 114, 11489-11495.

14 G. G. Gaitano, W. Brown and G. Tardajos, J. Phys. Chem. B, 1997, 101, 710-719.

15 P. Lo Nostro, J. R. Lopes and C. Cardelli, Langmuir, 2001, 17, 46104615.

16 T. Ooya, A. Ito and N. Yui, Macromol. Biosci., 2005, 5, 379-383.

17 C. Yang and J. Li, J. Phys. Chem. B, 2009, 113, 682-690.

18 J. Qin, X. Meng, B. Li, W. Ha, X. Yu and S. Zhang, J. Colloid Interface Sci., 2010, 350, 447-452.

19 T. Kataoka, M. Kidowaki, C. Zhao, H. Minamikawa, T. Shimizu and K. Ito, J. Phys. Chem. B, 2006, 110, 24377-24383.

$20 \mathrm{~J} . \mathrm{Li}, \mathrm{X}$. Ni, Z. Zhou and K. W. Leong, J. Am. Chem. Soc., 2003, 125, $1788-1795$.

21 J. Joseph, C. A. Dreiss, T. Cosgrove and J. S. Pedersen, Langmuir, 2007, 23, 460-466.

22 H. Fujita, T. Ooya and N. Yui, Macromol. Chem. Phys., 1999, 200, 706-713.

23 K. A. Udachin, L. D. Wilson and J. A. Ripmeester, J. Am. Chem. Soc., 2000, 122, 12375-12376.
24 A. Yamashita, D. Kanda, R. Katoono, N. Yui, T. Ooya, A. Maruyama, H. Akita, K. Kogure and H. Harashima, J. Controlled Release, 2008, 131, 137-144.

25 G. Wanka, H. Hoffmann and W. Ulbricht, Macromolecules, 1994, 27, $4145-4159$.

26 R. De Lisi and S. Milioto, Langmuir, 2000, 16, 5579-5583.

27 R. De Lisi, G. Lazzara, S. Milioto and N. Muratore, J. Phys. Chem. $B, 2004,108,1189-1196$.

28 E. Hecht, K. Mortensen, M. Gradzielski and H. Hoffmann, J. Phys. Chem., 1995, 99, 4866-4874.

29 R. De Lisi, S. Milioto, A. Pellerito and A. Inglese, Langmuir, 1998, 14, 6045-6053.

30 J. Kohlbrecher and I. Bressler, SASfit, a Program for Fitting Simple Structural Models to Small Angle Scattering Data; ETHZ \& PSI, Switzerland, 2009, http://sans.web.psi.ch/SANSSoft/sasfit.pdf.

31 J. S. Pedersen and M. C. Gerstenberg, Macromolecules, 1996, 29, 1363-1365.

32 N. W. Ashcroft and J. Lekner, Phys. Rev., 1966, 145, 83-90.

33 R. De Lisi, G. Lazzara, R. Lombardo, S. Milioto, N. Muratore and M. L. Turco Liveri, J. Solution Chem., 2006, 35, 659-678.

34 G. V. Schulz, Z. Phys. Chem., Abt. B, 1939, 43, 25-46.

35 P. Debye, J. Phys. Colloid Chem., 1947, 51, 18-32.

36 S. Borbely, Physica B, 1998, 241-243, 1016-1018.

37 R. De Lisi, M. Gradzielski, G. Lazzara, S. Milioto, N. Muratore and S. Prevost, J. Phys. Chem. B, 2006, 110, 25883-25894.

38 Z. Zhou and B. Chu, J. Colloid Interface Sci., 1988, 126, 171-180.

39 G. Wanka, H. Hoffmann and W. Ulbricht, Colloid Polym. Sci., 1990, 268, 101-117.

40 W. Brown, K. Schillen, M. Almgren, S. Hvidt and P. Bahadur, $J$. Phys. Chem., 1991, 95, 1850-1858.

41 G. E. Yu, Y. Deng, S. Dalton, Q. G. Wang, D. Attwood, C. Price and C. Booth, J. Chem. Soc., Faraday Trans., 1992, 88, 2537-2544.

42 K. Mortensen, J. Phys. IV, 1993, 3(C8), 157-160.

43 K. Mortensen, W. Brown and E. Jørgensen, Macromolecules, 1994, 27, 5654-5666.

44 M. Almgren, W. Brown and S. Hvidt, Colloid Polym. Sci., 1995, 273, 2-15.

45 P. Alexandriris, V. Athanassiou and T. A. Hatton, Langmuir, 1995, 11, 2442-2450.

46 I. W. Hamley, K. Mortensen, G. E. Yu and C. Booth, Macromolecules, 1998, 31, 6958-6963.

47 K. Mortensen, Polym. Adv. Technol., 2001, 12, 2-22.

48 E. Eiser, F. Molino, G. Porte and X. Pithon, Rheol. Acta, 2000, 39, 201-208

49 R. De Lisi, G. Lazzara, S. Milioto and N. Muratore, Phys. Chem. Chem. Phys., 2003, 5, 5084-5090.

50 R. De Lisi, S. Milioto, A. De Giacomo and A. Inglese, Langmuir, 1999, 15, 5014-5022.

51 R. De Lisi, S. Milioto and N. Muratore, J. Phys. Chem. B, 2002, 106, 8944-8953.

52 E. Junquera, L. Pena and E. Aicart, Langmuir, 1997, 13, 219-224.

53 G. Wenz, B. H. Han and A. Muller, Chem. Rev., 2006, 106, 782-817.

54 Y. He, P. Fu, X. Shen and H. Gao, Micron, 2008, 39, 495-516.

55 M. Nilsson, B. Hakansson, O. Soderman and D. Topgaard, Macromolecules, 2007, 40, 8250-8258.

56 G. Lazzara, S. Milioto and M. Gradzielski, Phys. Chem. Chem. Phys., 2006, 8, 2299-2312.

57 G. Lazzara, S. Milioto and N. Muratore, J. Phys. Chem. B, 2008, 112, $5616-5625$.

58 C. Dwyer, C. Viebke and J. Meadows, Colloids Surf., A, 2005, 254, 23-30.

59 U. Keiderling and A. Wiedenmann, Physica B, 1995, 213-214, $895-$ 897.

60 U. Keiderling, Appl. Phys. A: Mater. Sci. Process., 2002, 74, S1455S1457. 